\title{
Extreme Learning Machine Based Control of Grid Side Inverter for Wind Turbines
}

\author{
Şehmus FiDAN, Mehmet CEBECI, Ahmet GÜNDOĞDU
}

\begin{abstract}
The use of controller topology called back-to-back is becoming more widespread in full rated control of wind turbines. In back-to-back converter topology, to control the grid side inverter, it is necessary to control the dq currents and dc bus voltage using the vector control method. In order to perform the vector control method, it is important to know the LCL filter parameters used at the inverter output and to select the PI controller parameters in accordance with the obtained transfer function. In the classical design of the controller, the optimal modulus PI controller method is preferred because it facilitates the design process. In this study, as a new method, a controller structure called extreme learning machine based on single hidden layer feed forward artificial neural network is proposed to control the grid side converter. Since the proposed controller structure is analytically trained, it provides a faster solution than the iterative solutions of classical artificial neural networks. Various simulation results are presented on a wind turbine model in which permanent magnet synchronous generator is used to convert mechanical energy from the wind into electric energy. The modulation of the inverter used for energy conversion is performed by the sinusoidal pulse width modulation technique. The simulation results indicated that the extreme learning machine based controller provided successful results.
\end{abstract}

Keywords: back-to-back inverter; extreme learning machines; permanent magnet synchronous generator; wind turbines

\section{INTRODUCTION}

Generators that are one of the most important parts of wind turbines are manufactured in various types such as asynchronous, brushless DC and permanent magnet synchronous generators [1-4]. Due to the lack of need for the slip rings and brushes, a permanent magnet synchronous generator needs less maintenance, is of high efficiency, less noisy and has a long lifespan. Since PMSG can be connected directly to rectifier by the appropriate number of poles without the use of a gearbox, complexity, maintenance and cost can be reduced. In this case, it is possible to continue to produce power even at low wind speeds [5-8].

In addition to the various power electronic equipment and topologies for grid connection, IGBT- based inverter is frequently preferred to convert the energy, which is produced in the generator and transferred to the DC-link through controlled/uncontrolled rectifier, to 3-phase sinusoidal form [9-11]. The control of the grid side inverter is handled independently from the control structure of generator side controlled rectifier. The control of the grid side inverter basically determines the quality of power transferred to the grid and also provides integration and synchronization of this power to grid in accordance with regulations. In vector control method, active and reactive power is transferred from DC bus to grid by controlling $d$ and $\mathrm{q}$ current components. The synchronous reference PI controller and the stationary reference PR controller based vector control are the two frequently used methods in literature and Industry. In addition to these, other methods such as PI controlled synchronous virtual flux direct control, adaptive band hysteresis current control, space vector modulation-based direct power control, virtual flux direct power control have been shown in the literature [12, 13]. Passive filters are one of the most basic components of power electronics equipment used in converting DC bus voltage into 3-phase electrical energy at inverter output. Although there are various types of filters such as L, LC, LLCL to filter the inverter output voltage, LCL filter is preferred in this study $[23,24]$.
Unlike the other back-propagation artificial neural networks, in the extreme learning machine, which is defined as a single hidden layer artificial neural network method, the input layer and bias weights are assigned randomly. The training of extreme learning machines is provided analytically. Therefore, it provides a fast solution compared to the conventional iterative artificial neural network training. Since the output weights are solved using the inverse Moore-Penrose matrix, there are no problems affecting performance such as determining optimal learning parameters and stacking to local minimum [14, 15]. A sufficient number of trial/error is required to determine the number of neurons and activation function due to the network architecture of the extreme learning machine [16]. Wu et al. [17] used extreme learning machines to calculate the wind speed information needed to control the pitch angle of wind turbines. This study showed that ELM-based pitch angle control gives better results than conventional methods. Wang et al. [18] developed an ELM-based sliding-mode controller for autonomous underwater vehicles. A structure consisting of two cycles was proposed for control of depth and pitch angle. The pitch angle in the inner loop was controlled by an ELM-based sliding-mode controller and this method showed that the system is robust and stable. Matias et al. [19] proposed an online sequential extreme learning machine for adaptive system identification and model predictive controller in their study. In the study, the partial iterative least squares method was used instead of the iterative least squares method [20]. A solution to the problem of multiple linearity in online sequential ELM output layers was presented by this proposed method. In the same study, it was also mentioned that good results were obtained because the root mean square error (RMSE), which was developed for system identification and related to the generalized predictive control, was lower. Sato et al. [21] proposed an ELM-based adaptive PID controller for systems with first-order dead time. In order to determine PID parameters, the relation between tracking performance and robust stability was taken as a basis by using ELM. A result obtained by performing various simulations in Matlab/Simulink environment is presented in this study, in 
order to carry out the ELM-based control of the grid side inverter. As a result of the simulations, it is observed that the extreme learning machine based current controller tracked the d-q reference currents quite well for the control of the grid side inverter. Because there are few studies in the literature on the use of extreme learning machines as a controller, this article is an original study in terms of the use of extreme learning machines for the control of the grid side inverters.

\section{WIND TURBINE MODEL AND PERMANENT MAGNET SYNCHRONOUS GENERATOR}

The permanent magnet synchronous generator (PMSG) based wind turbine model in this study and the block diagram for the control structure of it are given in Figure 1. In the given model, the generator side controlled rectifier is used to convert the 3-phase AC voltage to DC voltage. The grid side inverter transforms the filtered DC voltage to $\mathrm{AC}$ voltage. The harmonic voltages at the inverter output are filtered by using the LCL filter. Thereby, harmonics are eliminated and the quality of the energy transferred to the grid is increased $[9,10,25]$. The explanations related to the wind turbine model whose control structure is given in Fig. 1 are presented in the subsections.

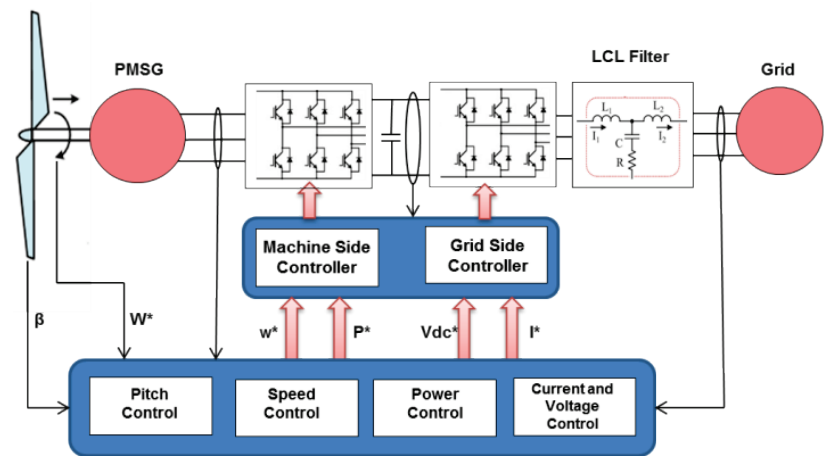

Figure 1 Grid connected wind turbine model and control structure

The power obtained from a wind turbine changes depending on the speed of the wind, air density, performance coefficient, and the swept area of the turbine blades [3].

$P_{\mathrm{w}}=\frac{1}{2} \rho A C_{\mathrm{p}}(\lambda, \beta) V^{3}$

$A\left(\mathrm{~m}^{2}\right), C_{\mathrm{p}}, P_{\mathrm{w}}, V, \rho\left(1.225\left(15^{\circ} \mathrm{C}-1\right.\right.$ atm. $\left.) \mathrm{kg} / \mathrm{m}^{3}\right), \beta\left(^{\circ}\right.$ pitch angle), $\lambda$ Tsr-Tip Speed Ratio) in Eq. (1) express the blade swept area, performance coefficient of wind turbine, turbine power, wind speed, air density, pitch angle, blade tip speed ratio, respectively. The tip speed ratio expressed by the blade radius and the wind speed is shown in Eq. (2). The swept area of the turbine blades can be determined by the equation of $A=\pi R^{2} / 4$. The performance coefficient $C_{\mathrm{p}}$ given in Eq. (3) is expressed as $\lambda$ and $C_{1}-C_{6}$ in terms of wing speed ratio.

$\lambda=\frac{R}{V}$

$$
\begin{aligned}
& C_{\mathrm{p}}(\lambda, \beta)=C_{1}\left(\frac{C_{2}}{\lambda_{i}}-C_{3} \beta-C_{4}\right) e^{\frac{C_{3}}{\lambda_{i}}}+C_{6} \lambda \\
& \frac{1}{\lambda_{i}}=\frac{1}{\lambda+0.08 \beta}-\frac{0.035}{\beta^{3}+1}
\end{aligned}
$$

$C_{1}-C_{6}$ coefficients have values of $C_{1}=0.517, C_{2}=$ $116, C_{3}=0.4, C_{4}=5, C_{5}=21, C_{6}=0.0068$, respectively. The torque obtained from the wind can be shown by Eq. (5).

$$
T_{\mathrm{w}}=\frac{P_{\mathrm{w}}}{\omega}
$$

The relation between performance coefficient $C_{p}$ and tip speed ratio $\lambda$ can be shown by the curve in Fig. 2 . According to Betz law, the theoretical maximum value of $C_{p}$ is 0.593 and the performance coefficient is maximum $C_{p}=0.44$ when $\beta=0^{\circ}$ and $\lambda=6.8$.

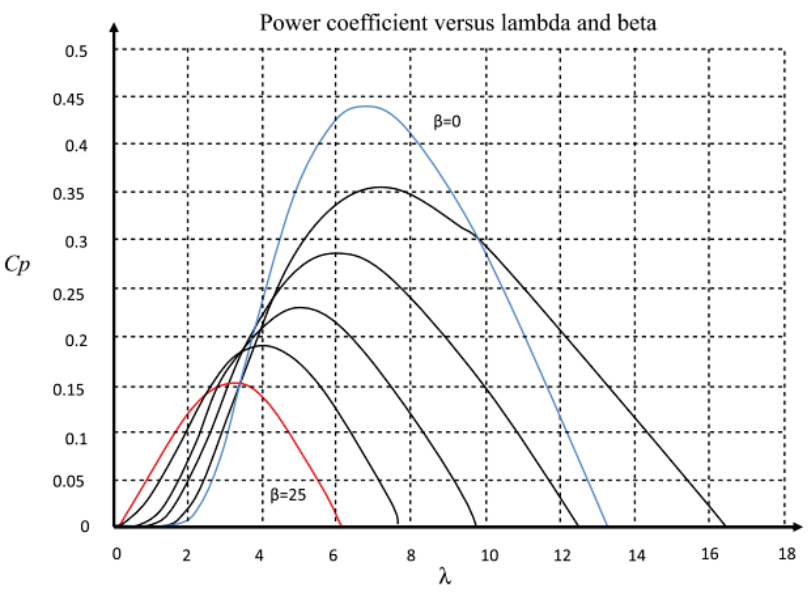

Figure 1 Performance coefficients corresponding to different $\beta-\lambda$ values

For each wind speed there is an optimal point where power is maximum. In addition, since operating of the turbine at each wind speed is not possible, the minimum and maximum cutting speeds of the wind turbine should be determined. While the wind turbine is closed below the minimum speed, the turbine blades are turned around their own at critical high wind speeds. In Fig. 3 the optimal points giving the maximum powers are indicated by the red line. The emerging curve is also expressed as $P-\omega^{3}$ curve.

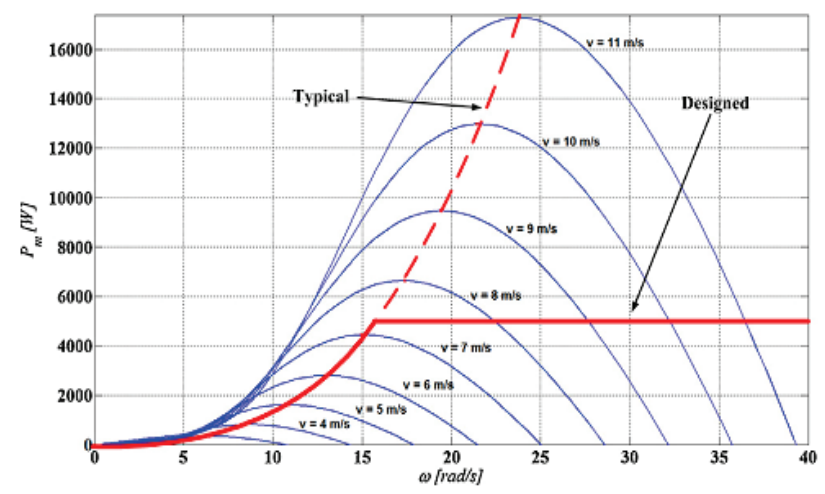

Figure 2 Turbine Output Power for Different Wind Speeds 


\subsection{Permanent Magnet Synchronous Generators}

Permanent magnet synchronous machines convert mechanical energy obtained from wind into electrical energy. The electrical and mathematical equivalent circuit model of PMSG can be easily demonstrated by using a $d q$ rotating reference frame [4-6]. $V_{s d}$ and $V_{s q}$ voltage expressions on the $d-q$ axis of the PMSG are given in Eqs. (6)-(7).

$$
\begin{aligned}
& V_{s d}=-R_{s} I_{s d}-L_{s} \frac{\mathrm{d}}{\mathrm{d} t} I_{s d}+L_{s} w_{e} I_{s q} \\
& V_{s q}=-R_{s} I_{s q}-L_{s} \frac{\mathrm{d}}{\mathrm{d} t} I_{s q}-L_{s} w_{e} I_{s d}+w_{e} \phi
\end{aligned}
$$

$L_{s}$ and $R_{s}$ are the winding inductance and winding resistance of PMSG, respectively. $\phi, w_{e}, I_{s d}$ and $I_{s q}$ indicate the magnetic flux, the electrical angles of the generator, the $\mathrm{dq}$ current components, respectively. Electromagnetic torque $T_{e}$ is expressed by:

$$
T_{e}=\frac{3}{2} p I_{s q}\left[\left(L_{d}-L_{q}\right) I_{s d}+\phi\right]
$$

where $L_{d}$ and $L_{q}$ denote the $d q$ axis inductances and $p$ shows the number of pole pairs. If $L_{d}$ and $L_{q}$ are equal, the electromagnetic torque can be written as follows.

$$
T_{e}=\frac{3}{2} p I_{s q} \phi
$$

\subsection{LCL Filter Model}

It is important to use a filter at the output of the grid side inverter and the type of the selected filter affects significantly the quality of the energy transferred to the grid. Fig. 4 shows the LCL filter structure connected between the inverter and the grid [23, 24].

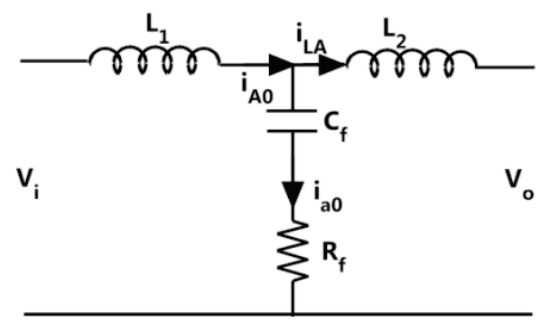

Figure $3 \mathrm{LCL}$ filter structure

The determination of the transfer function related to the LCL filter is very important in suppressing the voltage source harmonics and designing the controller. If $V_{o}=0$, without damping resistance $R_{f}$, the LCL filter can be shown by the transfer function in Eq. (10).

$$
H_{L C L}=\frac{1}{L_{1} C_{f} L_{2} s^{3}+\left(L_{1}+L_{2}\right) s}
$$

\subsection{Grid Side Inverter Model}

The mathematical model of the grid line voltages on the $d q$ axis is given in Eqs. (11)-(12).

$$
\begin{aligned}
& U_{d}=U_{i d}-R i_{d}-L \frac{\mathrm{d}_{i d}}{\mathrm{~d} t}+\omega L i_{q} \\
& U_{q}=U_{i q}-R i_{q}-L \frac{\mathrm{d}_{i q}}{\mathrm{~d} t}+\omega L i_{d}
\end{aligned}
$$

where $L$ and $R$ represent the grid inductance and resistance, respectively.

$U_{i d}$ and $U_{i q}$ are the $d q$ axis voltage components. If the reference plane is placed on the same axis with the source voltage, the grid vector voltage can be expressed as Eq. (13).

$u=u_{d}+j 0$

In this case, the active and reactive power can be given as Eqs. (14)-(15).

$$
\begin{aligned}
& P=\frac{3}{2} U_{d} i_{d} \\
& Q=\frac{3}{2} U_{q} i_{q}
\end{aligned}
$$

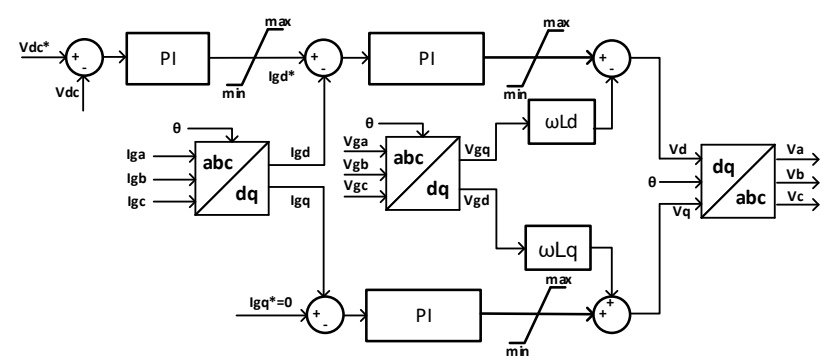

Figure 4 Vector control scheme of the grid side inverter.

Fig. 5 shows the general structure of the grid side inverter called vector control. In this structure, the outer loop is used to control the dc bus voltage and the inner loop is used to control the $d q$ currents. In the outer loop, $V_{d c}^{*}$ indicates the reference voltage value. $I_{g q}^{*}$ current is set to 0 so that the power transmitted to the grid is active power. In this study, the developed extreme learning machine based controller is proposed instead of the inside dq current controllers. The proposed controller structure is shown in Fig. 6.

Fig. 6 shows the block diagram of the extreme learning machine based vector control structure of the grid side inverter. On the grid side, 3 phase $\mathrm{AC}$ voltages are measured and phase angle $(\theta)$ information obtained through phase loop lock (PLL) is converted from 3 phase to $d q$ axis. The 2-axis $d q$ currents are obtained by using the phase loop lock block and the park transformation. Obtained currents are passed to a PI controller after they are compared with the reference currents and the error is detected. Finally, reference signals are generated by using $v_{d}, v_{q}$ voltages inverted by utilizing park and clark transformations. 


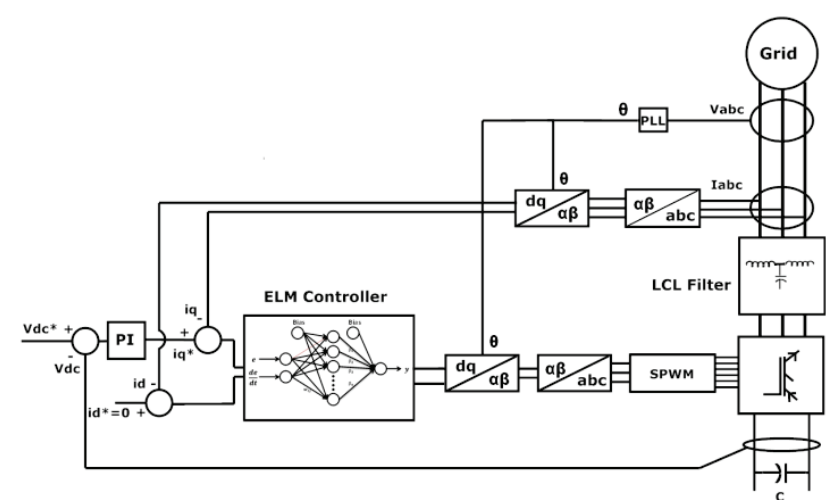

Figure 5 Extreme learning machine based controller structure of the GSC

\subsection{Extreme Learning Machine}

The extreme learning machine (ELM) is a feed forward artificial neural network learning method with a single hidden layer. This artificial neural network learning method assigns the input layer and bias weights randomly unlike the back propagation learning algorithms [14-16]. The network architecture of the ELM needs to be adequately tested to determine the number of neurons and the activation function. Fig. 7 shows the single layer neural network model that forms the basis ELM. Fig. 8 shows the flowchart of the ELM based neural network.

In Fig. $7, \beta_{1 \ldots m}, x_{1 \ldots n}, y_{1 \ldots p}, b_{i \ldots m}, w_{i, j}$ represent the weights regarding the output layer, the number of input layers, the number of output layers, the bias weights in the hidden layer, the weights between the input layer and the output layer, respectively. The layer regarding the output is expressed by Eq. (16).

$$
Y_{p}=\sum_{j=1}^{m} \beta_{k} f\left(\sum_{i=1}^{n} w_{i, j} x_{i}+b_{i}\right)
$$

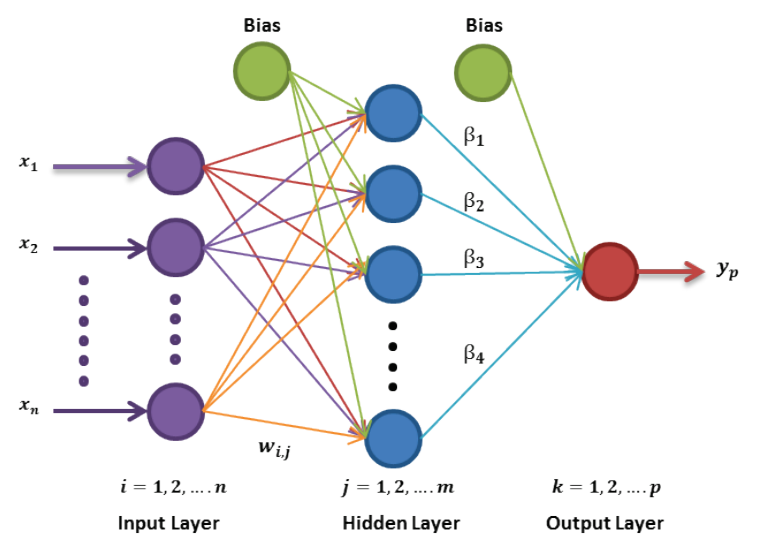

Figure 6 Extreme Learning Machine Network Model

The activation function in the generated network and the number of neurons in the hidden network are initially assigned. In addition, layer weights and bias values are assigned randomly at the beginning.

$$
\boldsymbol{H}\left(w_{i, j}, b_{j}, x_{i}\right)=\left[\begin{array}{ccc}
f\left(w_{1,1} x_{1}+\mathrm{b}_{1}\right) & \cdots & f\left(w_{1, \mathrm{~m}} x_{m}+\mathrm{b}_{m}\right) \\
\vdots & \ddots & \vdots \\
f\left(w_{n, 1} x_{n}+\mathrm{b}_{1}\right) & \cdots & f\left(w_{n, \mathrm{~m}} x_{m}+\mathrm{b}_{m}\right)
\end{array}\right]
$$

If Eqs. (16) and (17) are combined, Eq. (18) is obtained.

$$
\boldsymbol{Y}=\boldsymbol{H} \boldsymbol{\beta}
$$

Training methods in artificial neural networks mainly try to minimize the error. Likewise, extreme learning machines also minimize the error using functions called cost function $\left\|\sum_{k=1}^{s}\left(\hat{Y}_{k}-Y_{k}\right)^{2}\right\|$. The lowest possible error is obtained by minimizing the difference between the actual output value $\hat{Y}_{k}$ and the found value $Y_{k}$. If the Eq. (18) is examined, it will reveal that the value of $\beta$ must be found. The $\boldsymbol{H}$ matrix is not usually a quadratic matrix, so it is not possible to find the $\boldsymbol{\beta}$ weights by taking the inverse of the matrices. The generalized Moore-Penrose matrix is used to find the approximate inverse of the invertible matrices. When the generalized inverse matrix of $\boldsymbol{H}$ matrix is denoted as $\boldsymbol{H}^{+}$, the output weights can be given as the following expression:

$\hat{\boldsymbol{\beta}}=\hat{\boldsymbol{H}}^{+} \boldsymbol{Y}$

Here $\hat{\boldsymbol{\beta}}$ represents the approximate output weights.

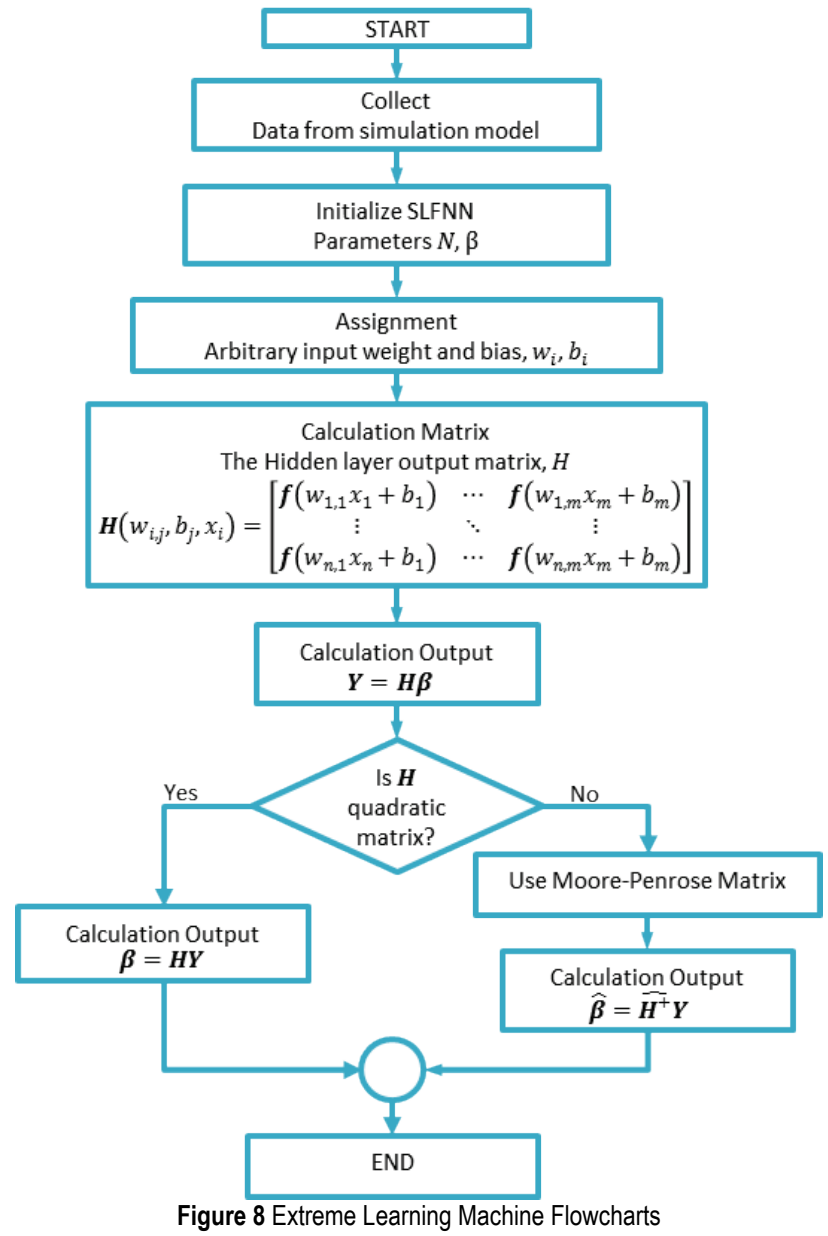

3 SIMULATION RESULTS AND DISCUSSION

The parameters of the grid side LCL filter must be known for the design of the internal loop $d q$ current controllers. Based on the filter parameters designed by referencing Reznik et al. [26], the controller parameters are calculated as $K_{p}=0.7518$ and $T_{i}=0.0028$, according to the optimal modulus method. The other parameters used in the 
simulation are given in Appendix A. As shown in Fig. 9, a forward layer artificial neural network is proposed to construct the model of the proposed extreme learning machine instead of the $d q$ axis PI controllers of the grid side inverter. As can be seen, the error and derivation of error are used as input, and the output is defined as the control signal output of the extreme learning machine.

A graph of mean square root errors is shown in Fig. 10 for different activation functions and neuron numbers in the training and test steps. It is clearly seen that sigmoid function gives more successful results. However, when this activation function is used, it is observed that there are no significant changes in root mean square error after 150 neurons. For this reason, results up to 150 neurons are added to the created table.

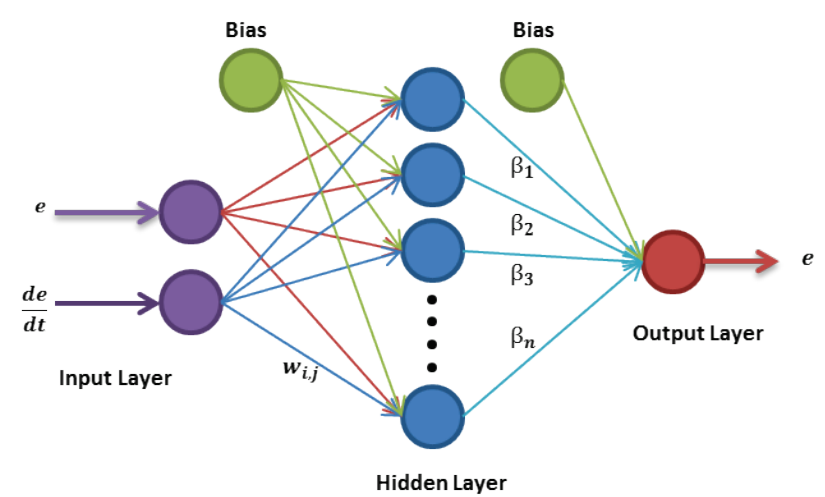

Figure 9 Generated artificial neural network model.
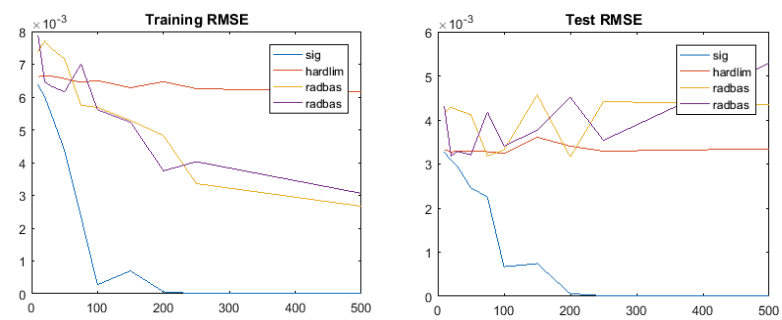

Figure 10 RMSE training and test performance for various activation functions of the artificial neural network.

Table 1 Mean squared error for various neuron numbers and activation functions

\begin{tabular}{|c|c|c|c|c|c|c|}
\hline \multicolumn{2}{|c|}{$\begin{array}{c}\text { Activation } \\
\text { Function }\end{array}$} & Sine & Sigmoid & Hardlim & Triangular & Radial \\
\hline \multirow{2}{*}{$\overline{\mathrm{D}}$} & 10 & 0.0039 & 0.0033 & 0.0033 & 0.0044 & 0.0043 \\
\cline { 2 - 7 } & 20 & 0.0035 & 0.0030 & 0.0033 & 0.0043 & 0.0043 \\
\cline { 2 - 7 } & 30 & 0.0036 & 0.0031 & 0.0032 & 0.0042 & 0.0033 \\
\cline { 2 - 7 } $\bar{\Xi}$ & 50 & 0.0037 & 0.0025 & 0.0034 & 0.0034 & 0.0040 \\
\cline { 2 - 7 } & 75 & 0.0034 & 0.0011 & 0.0033 & 0.0036 & 0.0033 \\
\cline { 2 - 7 } & 0.0008 & 0.0014 & 0.0033 & 0.0031 & 0.0057 \\
\cline { 2 - 7 } & 100 & 0.0009 & 0.0015 & 0.0034 & 0.0032 & 0.0067 \\
\cline { 2 - 7 } & 150 & 0.0009 & & & \\
\hline
\end{tabular}

Table 2 Solution times (sec) for various neuron numbers and activation functions

\begin{tabular}{|c|c|c|c|c|c|c|}
\hline \multicolumn{2}{|c|}{$\begin{array}{c}\text { Activation } \\
\text { Function }\end{array}$} & Sine & Sigmoid & Hardlim & Triangular & Radial \\
\hline \multirow{2}{*}{$\overline{\mathrm{D}}$} & 10 & 0.0035 & 0.0021 & 0.0023 & 0.0024 & 0.0022 \\
\cline { 2 - 7 } & 20 & 0.0022 & 0.0021 & 0.0022 & 0.0021 & 0.0021 \\
\cline { 2 - 7 } & 30 & 0.0041 & 0.0022 & 0.0020 & 0.0024 & 0.0024 \\
\cline { 2 - 7 } & 50 & 0.0032 & 0.0027 & 0.0032 & 0.0026 & 0.0023 \\
\cline { 2 - 7 } & 75 & 0.0057 & 0.0038 & 0.0042 & 0.0036 & 0.0032 \\
\cline { 2 - 6 } & 100 & 0.0097 & 0.0051 & 0.0041 & 0.0045 & 0.0037 \\
\cline { 2 - 7 } & 150 & 0.0071 & 0.0065 & 0.0051 & 0.0055 & 0.0047 \\
\hline
\end{tabular}

Tab. 1 shows the mean square error values for different neuron numbers and activation functions during the test step. The computation times of the computer processor depending on neuron numbers and activation functions during the test step are given in Tab. 2. It is seen from Tab. 2 that the sigmoid-activated extreme learning machine having 20 neurons in the hidden layer that provides the solution in the shortest time. The mean square error decreases as the neuron number of the values obtained in the test step of the extreme learning machine increases as shown in Tab. 1. However, the increasing of the neuron number extends the solution time, the network model with 20 neuron sigmoid activation functions has been determined as the most suitable model.
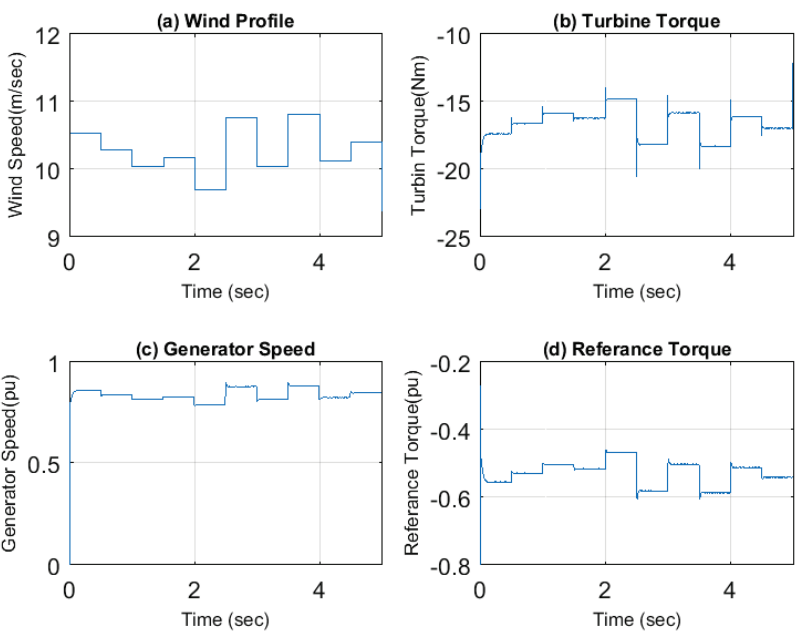

Figure 7a) Wind Speed b) Turbine Torque c) Generator Speed d) Reference Torque
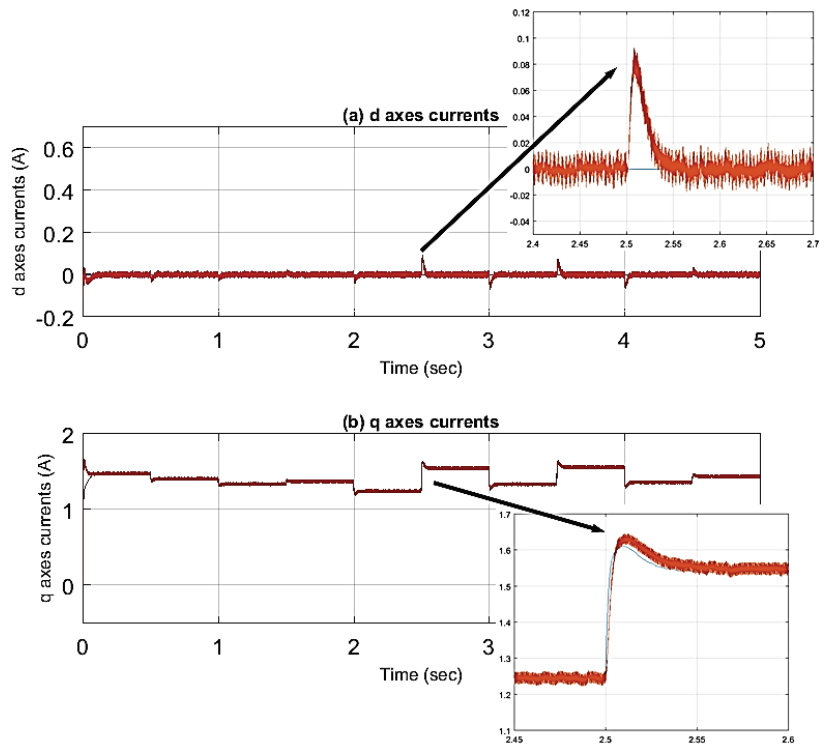

Figure 8 Machine side (a) $d$ axis (b) $q$ axis current

In response to the change in wind speed, Fig. 11(a): turbine speed, Fig. 11(b): turbine torque and Fig. 11(c): generator speed has been investigated in the simulation study. The generator speed is important for determining the $i_{q}$ reference current that is required for vector control of the permanent magnet synchronous generator. To obtain the torque information, the curve shown in Fig. 3 is utilized and the $P-w^{3}$ curve in which the maximum power is generated is used. The graph of the reference torque 
obtained by using the mentioned curve is given in Fig. 11(d).

Fig. 12 shows $d q$ reference and actual current values on the machine side. This graph shows that the actual load currents follow the $d q$ reference currents successfully.

Fig. 13 shows the response of the $d q$ current controllers in which the grid side extreme learning machine is used. As seen in the figure, the currents of the $d$ and $q$ axes follow the reference well. A graph of the DC voltage controller, which is part of vector control of the grid side inverter, is presented in Fig. 14. It follows the reference value set as 102 volts well.
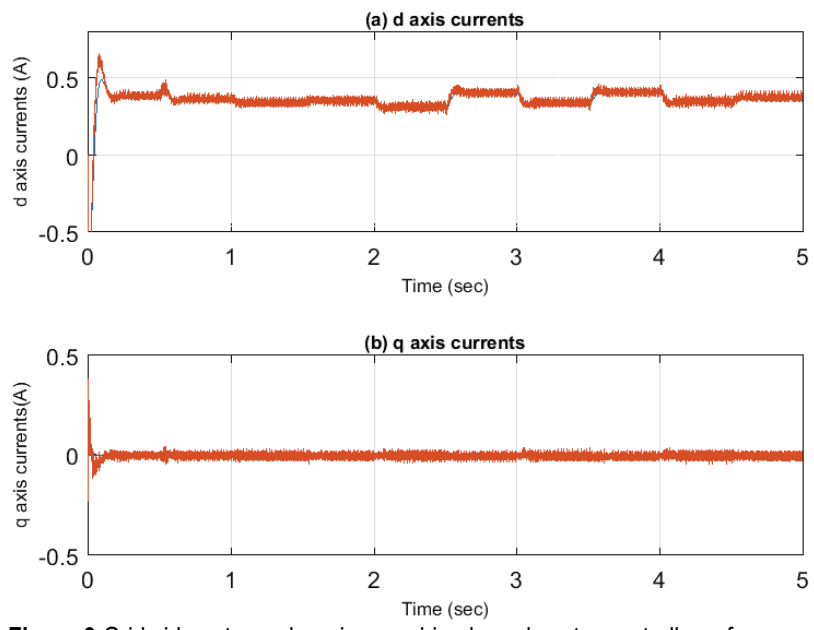

Figure 9 Grid side extreme learning machine based vector controller reference currents

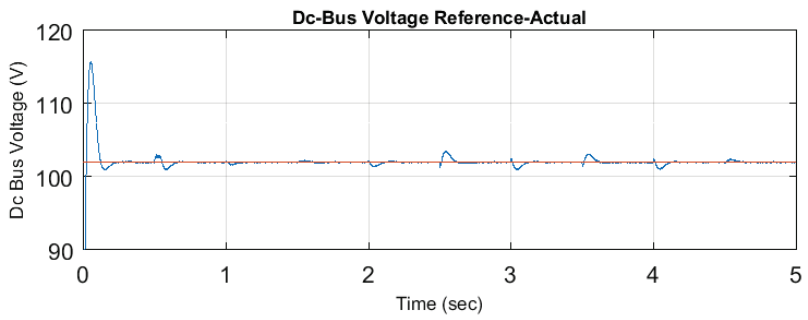

Figure $14 \mathrm{Dc}$ bus reference and actual voltages
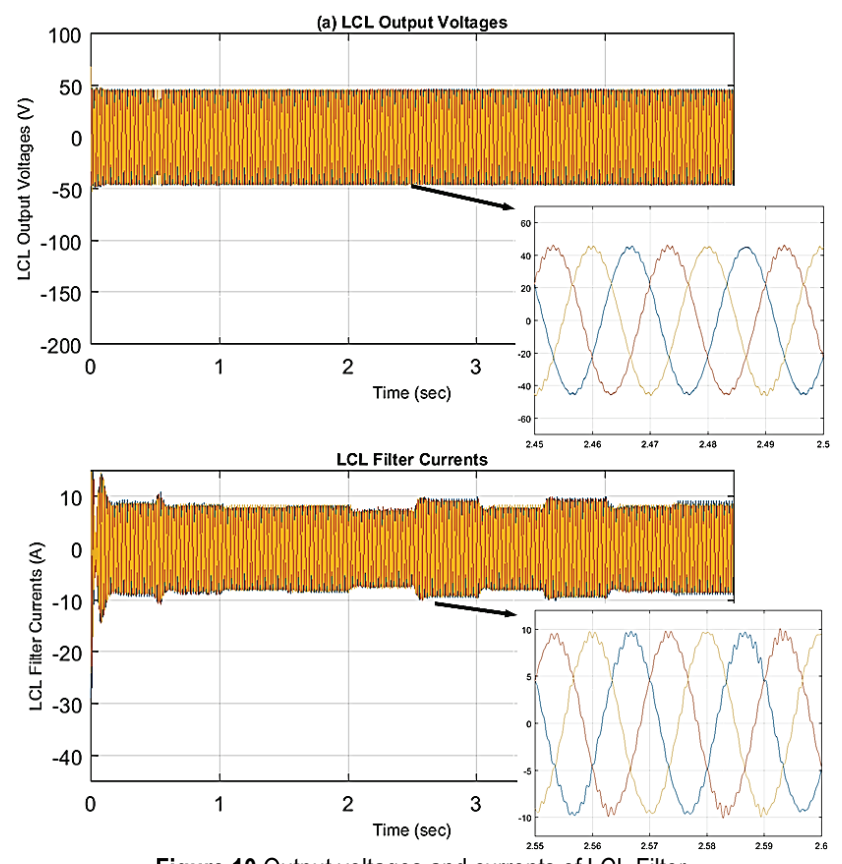

Figure 10 Output voltages and currents of LCL Filter
Fig. 15 shows the phase-to-ground voltages and currents plots at the LCL filter output. A $55 \mathrm{~V} / 380 \mathrm{~V}$ transformer is connected to the filter output before the grid connection. The changes in LCL filter output currents have been shown as a result of the change in wind speed.

\section{CONCLUSION}

In this study the back-to-back based inverter structure is used. The generator side inverter is controlled by the field oriented control method and the grid side inverter is controlled by the control method called vector control. Dc bus voltage is controlled by the PI controller in the outer loop while the $d q$ axis currents are controlled by PI controllers in the inner loop for the vector control of the grid side inverter whose general structure is shown in Fig. 5 . In this study, instead of the control of the $d q$ currents in the inner loop of the grid side inverter with PI controllers, the extreme learning machine based vector control is examined. Since the training of extreme learning machines, which is a single hidden layer artificial neural network model, is performed analytically, the model provides a faster solution than iterative solution methods of the conventional artificial neural networks. The LCL filter is used to filter the pulsed voltages at the output of the grid side inverter. In order to carry out simulation studies, the Permanent Magnet Synchronous Generator (PMSG) is used. The simulation results showed that the extreme learning controller with 20 neurons and sigmoid activation function follows the reference $d$ and $q$ currents well.

\section{Appendix-A}

\section{Generator Side Parameters}

$P_{\mathrm{g}}=1.5 \mathrm{~kW}, V_{\mathrm{g}}=3 \mathrm{faz} 110 \mathrm{VAC}, I_{\mathrm{g}}=8.3 \mathrm{~A}, w=2000$ $\mathrm{r} / \mathrm{min}, T_{\text {ork }}=7.16 \mathrm{~N} \cdot \mathrm{m}, R_{\mathrm{s}}=0.26 \mathrm{ohm}, L_{\mathrm{s}}=4.01 \mathrm{mH}$, Torque Constant $=0.87 \mathrm{Nm} / \mathrm{A}$, Voltage Constant $=31.8$ $V_{\text {peakL-L }} / \mathrm{krpm}$, Rotor Inertia $=11.18 \mathrm{~kg} \cdot \mathrm{m}^{2}, R=1.6 \mathrm{~m}$, Machine Side Current PI: $K_{p}=0.2, K_{i}=120$.

\section{Grid Side Parameters}

LCL Filter: $L_{2}=47 \mu \mathrm{H}, R_{\mathrm{f}}=1.2 \Omega, C_{\mathrm{f}}=10 \mu \mathrm{F}, F_{\mathrm{s}}=8$ $\mathrm{kHz}, V=3$ faz 55 VAC-RMS, $R_{1}=1 \Omega, C_{d c}=10 \mathrm{mF}$.

\section{REFERENCES}

[1] http://www.renewableenergyworld.com/ugc/articles/ 2014/11/history-of-windturbines.html, (15.10.2017)

[2] Tan, K. T., Lee, K. T., \& Mohamed, A. R. (2008). Role of energy policy in renewable energy accomplishment: The case of second-generation bioethanol. Energy policy, 36(9), 3360-3365. https://doi.org/10.1016/j.enpol.2008.05.016

[3] Ackermann, T. Ed. (2005). Wind Power in Power Systems. John Wiley \& Sons Ltd. https://doi.org/10.1002/0470012684

[4] Errami, Y., Maaroufi, M., \& Ouassaid, M. (2011). Modelling and control strategy of PMSG based variable speed wind energy conversion system. 2011 International Conference on Multimedia Computing and Systems, Ouarzazate, 1-6. https://doi.org/10.1109/ICMCS.2011.5945736

[5] Junfei, C., Hongbin, W., Ming, S., Weinan, J., Liang, C., \& Caiyun, G. (2012). Modeling and simulation of directly driven wind turbine with permanent magnet synchronous generator. Innovative Smart Grid Technologies - Asia, 2012 IEEE, 1-5. https://doi.org/10.1109/ISGT-Asia.2012.6303300 
[6] Husain, M. A. \& Tariq, A. (2014). Modeling and Study of a Standalone PMSG Wind Generation System Using MATLAB/SIMULINK. Universal Journal of Electrical and Electronic Engineering, 2(7), 270-277. https://doi.org/10.13189/ujeee.2014.020702

[7] Samanvorakij, S. \& Kumkratug, P. (2013). Modeling and simulation PMSG based on wind energy conversion system in MATLAB/SIMULINK. Proc. of Second Intl. Conf. on Advances in Electronics and Electrical Engineering (pp. 3741).

[8] Chen, J., Wu, H., Sun, M., Jiang, W., Cai, L., \& Guo, C. (2012, May). Modeling and simulation of directly driven wind turbine with permanent magnet synchronous generator. Innovative Smart Grid Technologies-Asia (ISGT Asia), 2012 IEEE (pp. 1-5).

[9] Baroudi, J. A., Dinavahi, V., \& Knight, A. M. (2007). A review of power converter topologies for wind generators. Renewable Energy, 32(14), 2369-2385. https://doi.org/10.1016/j.renene.2006.12.002

[10] Carrasco, J. M., Franquelo, L. G., Bialasiewicz, J. T., Galvan, E., Guisado, R. C. P., Prats, Ma. A. M., Leon, J. I., \& Moreno-Alfonso, N. (2006). Power-Electronic Systems for the Grid Integration of Renewable Energy Sources: A Survey. Industrial Electronics, IEEE Transactions on, 53(4), 1002-1016. https://doi.org/10.1109/TIE.2006.878356

[11] Melício, R., Mendes, V. M. F., \& Catalão, J. P. D. S. (2010). Power converter topologies for wind energy conversion systems: integrated modeling, control strategy and performance simulation. Renewable Energy, 35(10), 21652174. https://doi.org/10.1016/j.renene.2010.03.009

[12] Mehrzad, D., Luque, J., \& Cuenca, M. C. (2009). Vector control of PMSG for grid-connected wind turbine applications. Project for Master's Thesis, Institute of Energy Technology, Alborg University, Spring.

[13] Raducu, G. A. (2008). Control of grid side inverter in a B2B configuration for WT applications. PED10-1015b, Aalborg University.

[14] Huang, G. B., Zhu, Q. Y., \& Siew, C. K. (2006). Extreme learning machine: theory and applications. Neurocomputing, 70(1-3), 489-501. https://doi.org/10.1016/j.neucom.2005.12.126

[15] Huang, G., Huang, G. B., Song, S., \& You, K. (2015). Trends in extreme learning machines: A review. Neural Networks, 61, 32-48. https://doi.org/10.1016/j.neunet.2014.10.001

[16] Ertuğrul, Ö. F., \& Kaya, Y. (2014). A detailed analysis on extreme learning machine and novel approaches based on ELM. American Journal of computer science and engineering, 1(5), 43-50.

[17] Wu, S., Wang, Y., \& Cheng, S. (2013). Extreme learning machine based wind speed estimation and sensorless control for wind turbine power generation system. Neurocomputing, 102, 163-175. https://doi.org/10.1016/j.neucom.2011.12.051

[18] Wang, D., Shen, Y., Sha, Q., Li, G., Jiang, J., He, B., \& Yan, T. (2017, September). Controller design of an autonomous underwater vehicle using ELM-based sliding mode control. OCEANS-Anchorage, 2017 (pp. 1-5). IEEE. https://doi.org/10.1109/UT.2017.7890340

[19] Matias, T., Souza, F., Araújo, R., Rastegar, S., \& Mendes, J. (2014, October). Adaptive identification and predictive control using an improved on-line sequential extreme learning machine. Industrial Electronics Society, IECON 2014 - 40 th Annual Conference of the IEEE (pp. 58-64). https://doi.org/10.1109/IECON.2014.7048477

[20] Huang, G. B., Liang, N. Y., Rong, H. J., Saratchandran, P., \& Sundararajan, N. (2005). On-Line Sequential Extreme Learning Machine. Computational Intelligence, 2005, 232237.

[21] Sato, T., Tajika, H., Vilanova, R., \& Konishi, Y. (2018). Adaptive PID control system with assigned robust stability. IEEJ Transactions on Electrical and Electronic Engineering. https://doi.org/10.1002/tee.22680
[22] Georgina, F. P. (2010) Control of Grid Side Inverter for Wind Turbine PED4-1032, WPS4-1032, Aalborg University.

[23] Han, W. A. N. G., Chenzhao, Y. U., \& Jianwen ZHANG, X. C. A. I. (2012). Control of Voltage Source Inverter with an LCL Filter without Voltage Sensors. Przeglad Elektrotechniczny, 88, 119-122.

[24] Beres, R., Wang, X., Blaabjerg, F., Bak, C. L., \& Liserre, M. (2014, March). A review of passive filters for grid-connected voltage source converters. Applied Power Electronics Conference and Exposition (APEC), 2014 Twenty-Ninth Annual IEEE (pp. 2208-2215). https://doi.org/10.1109/APEC.2014.6803611

[25] Murthy, S. S., Singh, B., Goel, P. K., \& Tiwari, S. K. (2007). A Comparative Study of Fixed Speed and Variable Speed Wind Energy Conversion Systems Feeding the Grid. Power Electronics and Drive Systems, 2007. PEDS '07. $7^{\text {th }}$ International Conference on, 736-743, 27-30 Nov. https://doi.org/10.1109/PEDS.2007.4487785

[26] Reznik, A., Simoes, M. G., Al-Durra, A., \& Muyeen, S. M. (2014). \$ LCL \$ filter design and performance analysis for grid-interconnected systems. IEEE Transactions on Industry Applications, 50(2), 1225-1232. https://doi.org/10.1109/TIA.2013.2274612

\section{Contact information:}

Sehmus FIDAN, PhD Student

(Corresponding author)

Batman University,

Batı Raman Campus, 72060 Batman, Turkey

sehmus.fidan@batman.edu.tr

Mehmet CEBECi, Prof. PhD

Fırat University,

Central Campus, 23119, Elazığ, Turkey

mcebeci@firat.edu.tr

Ahmet GÜNDOĞDU, Associate Prof. PhD

Batman University,

Batı Raman Campus, 72060, Batman, Turkey

ahmet.gundogdu@batman.edu.tr 